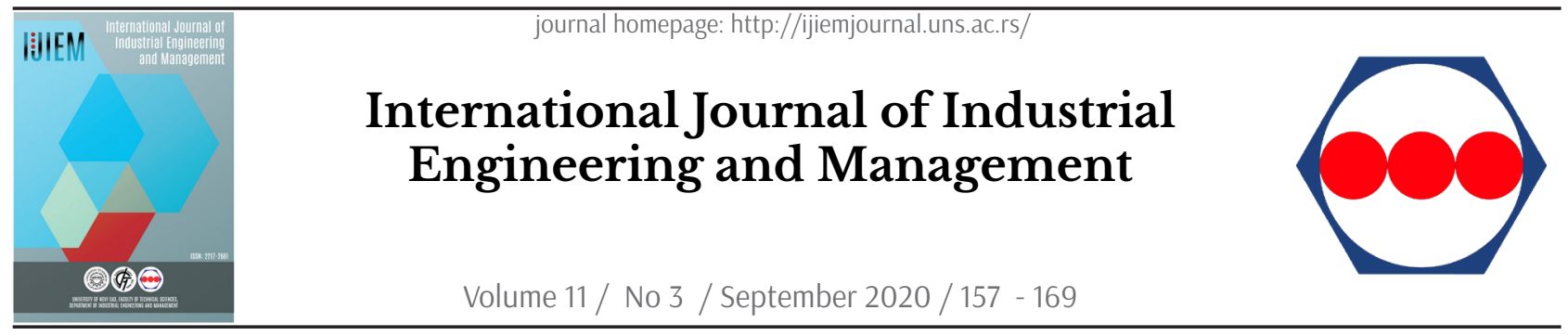

Original research article

\title{
Development of Lean Manufacturing Implementation Framework in Machinery and Equipment SMEs
}

\author{
C. Jia Yuik *, P. Puvanasvaran \\ Universiti Teknikal Malaysia Melaka, Faculty of Manufacturing Engineering, Melaka, Malaysia
}

\begin{abstract}
A B STRACT
Small and medium-sized enterprises (SMEs) are lag in lean manufacturing (LM) implementation. The purpose of this study is to develop an effective LM implementation framework, which serves as a practical guideline specifically in machinery and equipment SMEs. Semi-structured interviews are conducted with selected multiple case study respondents. The proposed framework consists of four sequential implementation stages which include 23 essential components to suit the SMEs characteristics. It adopts the PDCA (Plan-To-CheckAct) cycle approach and aligns with company working approaches. This simple and comprehensive framework can assist SMEs lean practitioner in their LM implementation journey systematically and improve the organization's performance.
\end{abstract}

\author{
ARTICLE INFO \\ Article history: \\ Received May 27, 2020 \\ Revised August 30, 2020 \\ Accepted September 1, 2020 \\ Published online September 10, 2020 \\ Keywords: \\ Lean manufacturing; \\ Machinery and equipment; \\ Small and medium-sized enterprises; \\ Lean implementation framework; \\ Manufacturing \\ *Corresponding author: \\ Chong Jia Yuik \\ chongjiayuik@gmail.com
}

\section{Introduction}

In the competitive economic environment, small and medium-sized enterprises (SMEs) worldwide are always looking for a better opportunity in continual improvement towards their business market transformation. SMEs play an essential role in contributing to the manufacturing industry. SMEs are striving hard to cope with the challenges to make them stay competitive with the other large organizations, especially in this Industrial Revolution 4.0. One of the popular manufacturing approaches that can be practiced by SMEs to increase production efficiency and create value-added to customers is via lean manufacturing (LM) implementation [1]-[4]. Value is defined as any product or service that a customer would be willing to pay for from their working perspectives [5]. Manufacturing companies that are implementing lean will benefit from a variety of advantages, such as profit generations and expand the business market growth [6]-[8]. In the manufacturing industry in Malaysia, SMEs are defined as firms having a sales turnover not exceeding RM50 million or with the number of fulltime employees not exceeding 200 [9]. SMEs are the backbone of the economy, and $98.5 \%$ of business establishments in Malaysia are SMEs. Malaysia's SMEs GDP achieved a numerous growth at $6.2 \%$ exceeded Malaysia's GDP which recorded at $4.7 \%$ in 2018. The SMEs GDP contribution increased to $38.3 \%$ as compared to $37.8 \%$ in 2017 [10]. In the 11th Malay- 
sian Program, the machinery and equipment (M\&E) industry is regarded as a catalyst for the transition to greater economic growth in the country. In addition, the $\mathrm{M} \& \mathrm{E}$ industry contributed a total of RM40.5 billion (USD 10.3 billion) in exports in 2018. It is anticipated that this figure will rise at an average annual rate of $4.1 \%$ by 2020, reaching RM 43 billion (USD 10.9 billion) [11]. LM has been applied in manufacturing industries extensively, such as in the automotive sector, but there is still a lack of research focusing on the LM framework application in the $\mathbf{M} \& \mathbf{E}$ sector. There are some weaknesses and barriers that hinder LM implementation due to several factors such as lack of suitable LM framework specifically designed for SMEs to follow and always caused the LM initiative to fail [12]. There is no standard LM implementation process framework, as none of the available frameworks or models on LM provides a stepwise guideline or process to implement LM [4]. Besides, most of the LM frameworks are developed for large manufacturing companies, but lack of attention to SMEs [13]. The most common problem in implementing lean concepts for SMEs is the lack of understanding of the concept itself and its principles [14]. Although many enterprises succeed in applying LM around the world, less than $20 \%$ of them have sustained lean activities for an extended period [15]. This showed SMEs still must explore the best way of LM implementation to suit their needs. There are many various types of existing LM implementation frameworks that had been proposed by researches or academicians for application in different sectors of the industry. However, M\&E SMEs still find it difficult to implement LM and they are not able to enjoy similar benefits as other large organizations. This study aims to explore the current LM approaches adopted in M\&E SMEs and develop a systematic LM framework to overcome the limitation of the existing frameworks. It will be beneficial for SMEs lean practitioner and manager to utilize the right approaches to start their lean journey effectively for continuous improvement and transform to a higher level.

This paper is presented in five sections: the first section introduces the LM implementation overview and research objectives. The second section discusses the literature review of the existing LM implementation frameworks for SMEs and current research gaps. The research methodology and case company general background is described in the third section. The fourth section contains the different case studies data collection and analysis of their LM implementation methodology adopted. This is followed by the development of the proposed new LM implemen- tation framework and discussion of the framework's features. The last section presents the conclusions with the limitation of the study and future works recommendations.

\section{Literature review}

LM is originated from Toyota Production System (TPS) [16] and later popularised by the book titled "The Machine That Changed the World" [17]. The main aim of the LM concept is to eliminate non-value-added activities generally referred to as waste. Three primary enemies of lean in the production system are Muda (waste), Mura (unevenness), and Muri (overburden) [18]. The seven forms of wastes, which are overproduction, waiting, transportation, excess processing, inventories, motion, and defects [16]. The proposed five key lean principles start with identifying value from the voice of customer, mapping value stream which specifying the process creating the value; the process should run in a continuous flow to deliver quality product just in time to the customer; Pull system prevents any overproduction and finally, continuously improve the system in the pursuit of perfection [19]. These key principles must first be understood before implementing LM in SMEs [21]-[22]. The most substantial challenge encountered by SMEs is to know which principles, tools and practices to implement and how to effectively apply them in problem-solving [12]. LM also applies to different industries or organizations irrespective of their size [17]. SMEs' organizations adopted LM system implementation contributes to operational excellence, improves customer satisfaction, increases profitability with competitiveness growth [2],[7]. The motivations for SMEs in choosing LM are to solve critical issues and achieve business performance sustainability.

\subsection{Review of Existing LM Implementation Frameworks}

The goal of LM is to respond to customer demand with the aim of waste elimination at the lowest cost [4]. A framework consists of a set of simplified structures that are easy to understand and the organizations can adopt it systematically for effective implementation [22]. The lack of a well-structured implementation plan for SMEs is the reason why lean practices are less likely to be successful [23]. Therefore, the development of the suitable LM framework in SMEs is fundamentally essential to allow lean practitioners to clearly understand the critical elements 
and requirements needed for implementing LM successfully. The development of a suitable framework must satisfy these proposed set of characteristics criteria when considered applicable for SMEs [24]:

(1) Systematic and easily understood

(2) Simple in the structure

(3) Having clear links between the elements or steps outlined

(4) General enough to suit different contexts

(5) Represent a road map and a planning tool for implementation

(6) Answers "how to?" and not "what is?" the initiative approach

(7) Implementable in SMEs

Systematic literature review of the frameworks for lean implementation in SMEs reveal that there is still a gap in presenting a simple, adapted and verified framework that takes into account the specific needs and requirements of SMEs in terms of size constraints and with a strong connection to their overall strategy [25]. Several essential components (implementation process steps, lean tools, and success factors) in three phases LM implementation framework derived from the successful lean experiences of four manufacturing case SMEs were presented [12]; however, there is limited discussion of the current existing LM framework presented in terms of SME's dimensions and the proposed framework requires more critical elements or other experiences for enrichment. The comprehensive LM implementation roadmap in multinational companies in Brazil was developed in five stages as a practical guideline [26]. The project-based lean implementation framework investigated 28 lean initiatives with nine critical success lean factors systematically in four phases [27]. However, these two proposed frameworks are not designed specifically to suit the SMEs requirements and recommend a practical validation in the actual case study. The framework of critical success factors for lean implementation in Vietnam manufacturing enterprises in six dimensions was discussed [15], but the framework was not able to answer how to implement the approach. The simple conceptual framework using eight steps of Kotter's model based on change management theory was proposed [28]. This model did not include the process steps in terms of operational perspective. A comprehensive conceptual framework for LM excellence was presented [29]. The pillars of LM and respective elements did not represent a roadmap and planning tool for LM implementation. The conceptual framework adopt- ed 11 essential soft lean practices (human-related aspects) towards the successful LM implementation in Malaysia SMEs, but it does not discuss the importance of other hard lean practices (LM technical tools) elements and there is no clear link between these elements [30]. The theoretical LM framework using two case study approach in the printing industry showed that a lack of systematic guide and the structure outlined was not straightforward [31]. The simple lean supply chain performance framework in a food manufacturing SME based on various performance measurement scorecards was developed [32]. It is recommended that other lean critical success factors and lean tools practices should be emphasized in LM implementation. A framework for LM implementation which consists of three major phases was developed from a review of frameworks based on the eight critical parameters [33]. However, this conceptual framework has not proven it is implementable in actual case SMEs and did not emphasize on other lean critical success factors such as the organizational culture change aspect.

\subsection{Research Gap and Problem Identification}

A lean organization is characterized as an organization that upholds key lean performance aspects that are suitable for all management's functions. It is considered as a broad concept of integration system to improve the process efficiency in value creation. There is no unique framework for smooth lean implementation from the study, as it needs to be customized to each organization [13]. The systematic reviewed of the available lean framework which considered universal or perfectly suits for applicability in SMEs based on their specific characteristic is very limited [25]. Therefore, it would be worthwhile to study this LM phenomenon more contextually and specifically in an industry cluster for M\&E. The review of the existing LM implementation frameworks identifies that there is a lack of practical framework as straightforward guidance in the context of $M \& E$ SMEs. There is a lack of organizational change management methodology for SMEs in their LM implementation readiness, especially involving know-how techniques when adopting the changes. Nonetheless, the existing LM implementation frameworks and approaches introduced are more focused on the lean concepts or principles than a sequence of steps. Although several frameworks have been presented, many companies still find it challenging to implement lean and have a great impact on unsuccessful results [13]. Furthermore, most of these frameworks do not 
examine the detail of LM practices correspond to the current approaches used in the case companies. Therefore, there is a strong need to propose an effective framework that is explicitly designed to serve as a useful guideline for $\mathrm{LM}$ implementation in $\mathrm{M} \& \mathrm{E}$ SMEs in an attempt to fill up this gap.

\section{Methodology}

In Malaysia, M\&E sector is classified into four major sub-sectors [11]: Specialized process machinery or equipment for a specific industry, metalworking machinery, power generating $\mathbf{M} \& \mathbf{E}$, and general industrial M\&E, components, and parts.

There remains limited insight of LM adoption for M\&E sector in Malaysia, as most research has been primarily conducted in the automotive industry [34]. Therefore, the selection criteria for the study area were $\mathbf{M} \& \mathbf{E}$ companies that met the definitions of Malaysian manufacturing SMEs. All the case companies should have at least one year of LM implementation experiences regardless of their success or not in lean attempting. There are three case SMEs that showed a strong interest and willingness to involve in this study. The purposive sampling is employed for the selection of targeted case companies, as the respondents can provide the best information to describe the detailed LM implementation situation in achieving the aim of this study. The general profile of the three case companies is shown in Table 1.

The qualitative study by using the semi-structured interview with open-ended questionnaires was employed. The interview questionnaires were slightly adapted to suit the study and divided into two sections as following [31]:

(1) The first part describes the company profiles and motivation to implement LM.

(2) The second part explores the lean tools implemented in the company, the methodological approach used in LM process steps and critical challenges faced.

The questionnaires established were validated by two local university academicians who are experts in the LM field before the pilot interview. Pilot interviews were conducted during the initial appointment with the case SMEs senior management staff to explain the overall research plan and objectives study before scheduled the actual interview. Draft questionnaires were also issued to them to verify the content on the same day. This is to confirm that SMEs respondents understand the meaning of the questions and to prevent any wrong interpretation. The useful feedback and recommendations were then reviewed along with minor adjustments made to the questionnaires before certifying the finalized data collection instruments were acceptable for the actual interview. Three staff (Table 2) were selected to represent each case company from the management level to respond in the face-to-face interview. This is to ensure the answers can have wider coverage and

Table 1. Case studies company profile informatio

\begin{tabular}{llll}
\hline Company Name & A & B & C \\
\hline Establishment year & 1990 & 2006 & 1997 \\
Company ownership & Family own & Joint venture & Joint venture \\
No. of full-time employees & 32 & 60 & 40 \\
Year sales turnover (RM) & Within 5 million to 10 million & Within 5 million to 10 million & Within 10 million to 15 \\
& range & range & million range \\
Main products & Rubbery machinery & Surface treatment & Industrial wires \\
Certifications / achie ements & Achieved SMEs SCORE 4 star & ISO 9001:2015; AS9001; & ISO 9001:2015; ISO \\
& $(2019)$ & NADCAP; SME Award 2015 & 14001:2015 \\
No. of years in LM implementation & $\approx 3$ years & $\approx 7$ years & $\approx 15$ years \\
Type of M\&E sub-sector & Specialized process in the & Specialized process in the & General industrial in \\
& agriculture industry & aerospace industry & components and parts \\
\hline
\end{tabular}

Table 2. SMEs interview respondent's designation and management level

\begin{tabular}{llll}
\hline Company / Respondents & A & B & C \\
\hline Senior management & Senior engineering manager & Senior factory manager & General manager \\
Middle management & R\&D manager & Planner & Business manager \\
Bottom managemen & Finance executive & Quality engineer & QC executive \\
\hline
\end{tabular}


generalize from different levels of the organizations. Each interview session was conducted within one to two hours in the company premises to accommodate the respondent's schedules. Site plant tours were also arranged for validation of interview responses, as this can generate a clear overall view of the working approaches and operation practices via direct observation. The interviews were communicated using respondent's mother tongue languages and recorded in audio for transcribed it into the text form for data analysis after granted permission from SMEs.

\section{Results and discussion}

\subsection{Case Study Company A}

Company A primarily manufactures rubber machinery since 1990. It provides the design and installation of natural rubber processing machinery according to customer needs, primarily focus on automation. Top management aims the lean concept could bring drastic transformation to production efficiency, working culture change, and upgrade the employee skill competency. The company mission clearly defines the strategy to strengthen the fundamental of LM concept application, followed by the incorporation of latest technology in the future. LM projects are usually initiated through a top-down approach from senior management. During the pre-implementation phase, tasks are passed down to the responsible shop floor employees through a short briefing or quick discussion. The intention for LM implementation was identified which normally to solve the operational production issues. The project selection is based on the easiest to implement such as in the intermediate bulk containers areas which were started on a small scale. There is no specific stepby-step process framework planning to follow during the lean project implementation. The most practiced lean tool in SMEs is the $5 \mathrm{~S}$, which has the highest presence frequency from the systematic literature review [25]. 5S housekeeping was adopted as a fundamental starting point for LM process improvement in the identified equipment storage area in the year 2018, which caused the significant loss of waiting time searching for tools during operation hours by maintenance employees. Middle management takes the lead on the lean project as assigned, and line leader will work with the shop floor employees in execution parts by following the instruction given. The operators monitored the $5 \mathrm{~S}$ progress and highlighted to the line leader to require help needed. Senior management will review the lean result regularly with the manager in-charged and make the key decision based on the result. There is no official on job training related to LM previously. Therefore, senior management highlighted that it is vital to invest in lean training to upgrade employee knowledge. This can build-up the right lean thinking mindset and apply learning in the workplace. Most of the shop floor employees practiced the basic 5S, especially in the first 3S: Sort, Set in Order, and Shine without a deep understanding of the lean concept philosophies. The last " $2 S$ " in the $5 \mathrm{~S}$ which namely Standardize and Sustain, were not rigorously follow up with persistent execution. $5 \mathrm{~S}$ was performed only during the non-routine period with low priority and employees felt it was an additional task. The shop floor employees implemented $5 \mathrm{~S}$ as an ad-hoc job and only practicing it on and off when instructed. The continuous improvement initiatives and lean project implementation roadmap were not in place to sustain the $5 \mathrm{~S}$ system actively. Company $\mathrm{A}$ is still not clear on how to implement lean effectively, and what to apply with the lean concept. There is no alignment in the common goals between the management and the shop floor employees due to a lack of two-way open communication. This caused the lean results to fail during halfway and end up not able to deliver the expected outcomes. In summary, company A still considered as lean beginner with low level of implementation. The LM application is fragmented and unsuccessful. The R\&D manager claimed: "LM implementation framework is essential for lean beginners, as a useful guideline to establish knowhow application with mitigating the risks and pitfalls".

\subsection{Case Study Company B}

Company B provides a full-service custom metal finishing company with many years of experience in surface treatment industries. Nowadays, it owned a total land size of 72,000 square feet with housing a wide range of process capabilities catering for various industries, which primarily is from the aerospace sector. The motivation for lean adoption is to achieve customer satisfaction and improve production efficiencies. The extensive application of lean tools in company B are including kaizen, Gemba, one-point lesson (OPL), 5S, visual control, and standard operation procedure (SOP). The managing director is very supportive of the lean initiatives and always motivating the employees to suggest improvement ideas. For example, the managing director will bring in the latest news information collected through the customers, suppliers, and even competitors. The valuable experiences and latest technology exchanged are obtained 
via the aerospace conferences, air show, and so on. LM is not the new subject to company B and they had transformed a high understanding of lean principles into actual implementation from the interview with respondents. Company B started LM on a small scale and gradually expanded across the other critical areas. The factory manager will oversee the entire LM implementation and having daily communication with employees in the production meeting. LM project is led by the respective managerial level staff with cross-functional team collaboration between the relevant department involved. Company B normally will use the currently available resources in LM implementation unless the lean project is worth the return of investment, and this also subjected to managing director approval. It actively identified the opportunity for improvement in waste elimination, through the solid lean foundation established for seven years ago. For example, the OPL was implemented in the year of 2014, which serves as quality alert communication to the shop floor employees. The visual control board was used to display the simple OPL to remind the employees of the correct way of doing things. The top management will regularly review the progress of lean projects and discussed the next course of action planned with middle management. The managing director is always open to the employee for discussion whenever they face the difficulties and encourage the employee to think creatively on problem-solving in the workplace. Middle management highlighted that the employees are practicing learned by doing in their work areas independently with the steps-by-steps guidance and coaching from experienced senior staff until mature. Job rotation is delegated as an opportunity to improve the employee's lean knowledge skills and to grow their self-development. The employee's high involvement and empowerment given in the LM implementation improvement projects also bind to individual performance indicators assessment criterion for promotion. The key challenges faced by Company $\mathrm{B}$ come from the shop floor employees are not familiar with the lean tools and tend to make simple mistakes. Therefore, comprehensive lean training was conducted periodically through organized workshops and seminars by qualified internal trainers. Besides that, lean projects were monitored closely, and lean indicators data were collected for detailed analysis. The management demonstrated its commitment by monthly reviewing lean status and established the result-oriented rewards system as recognition. Company $\mathrm{B}$ is emphasizing the post-implementation of LM by assessed the main lesson learned and documenting the good lean practices for continuous im- provement in large scale run. In short, the LM implementation in Company $\mathrm{B}$ is at a moderate level and the success is restricted to departmental level. The lean achievement was acknowledged by valued customers with providing positive feedback for further enhancement. The planner from company B stated: "A good LM implementation framework can be used as a reference guides in strategy planning and forms the important steps through systematic working instructions, and it must be adaptable to suit different company needs".

\subsection{Case Study Company C}

Company C was formed in the year 1997 to manufacture industrial wire. It provides a wide range of advantages in producing the wire as customized by the customers with different types of imported machines. The motivation to adopt lean is to achieve business survival in the competitive global market and improve the quality standard to meet customer requirements. The company claimed that they had implemented the lean tools since many years ago but did not aware that it is related to LM implementation. The executive-level staff is still not familiar with the in-depth lean concept and terminology. The lean tools adopted in Company $\mathrm{C}$ are kaizen, Gemba, 5S, visual display, SOP, and work instruction. Company C started the LM implementation since 2004, aligned with its effort to achieve the ISO 9001 certification, as there is a close relationship between the quality management system process compliance in connection with the integration of lean tools concepts such as work standardization and continuous improvement. The defect of products was the primary form of wastes in the prioritization of lean project selection. For example, major defective products such as rejection of wire entanglement would return from the customer for sorting and rework, and this causes unnecessary high productivity loss and cost of quality. The internal lean training was conducted in response to the critical quality issues raised by emphasizing lean awareness and preventive measures. There is no specific lean subject matter expert in conducting the intensive lean training to the employees and they did not engage the lean consultant for support. The weekly internal meeting will be called up to discuss the non-conformance issues and brainstorming for practical solutions. The production supervisors will provide the steps-by-steps coaching to the relevant operators by following the SOP documents with practical demonstration until they are fully aware of it. The SOP was transferred into the work instruc- 
tions format to ease their understanding of the standard steps described. Simple words translation and visual aid tools such as video were adopted to break the language barriers faced by foreign workers. The senior management has shown excellent leadership commitment by allocating the necessary resources needed in lean projects. LM implementation was led by middle management with the relevant executive staff to execute the implemented system in a teamwork manner. A lean committee was formed to plan the LM projects and assess the risks. The general manager (GM) will arrange the Gemba walk with the management team to have a quick understanding of the problems that happen on the production floor and discuss the improvement action plan for the solution. The lean result was reviewed by the GM as a key decision-maker to make the final call, and the approved procedures were documented. The key barrier faced by management during the LM implementation is the lack of lean knowledge among the shop floor employees and this requires a longer time to convince them for early lean engagement. Middle management revealed that the importance of management to lead by example in LM implementation to motivate the cultivation of strong teamwork and positive working culture change. Senior management also underlined the integration of lean management system to daily work to effectively deal with the production problems and create value-added to the customers. The management team is very committed to achieving lean success through workforce skill transformation in alignment with the company policy to get customer recognition. Senior management believed that LM is the essential strategy for their continuous improvement growth in the organization and the emphasis of lean could assist in streamline the operation flow efficiency in the large-scale run. LM implementation in Company $\mathrm{C}$ is still at the low to moderate level and the LM achievement is slightly successful due to lack of standardization in lean tool's practices. To quote from the GM: "LM framework is vital for SMEs since it serves as a standardized stepby-step implementation outline for lean practitioners in effective problem-solving".

\subsection{Analysis of LM Implementation Methodology Used in Case Study SMEs}

SMEs should exploit their strengths and better cope with their weaknesses when conducting the LM implementation framework while making any changes, as SMEs tend to be more flexible, able to respond quickly, have talented human resources, and suffer less bureaucracy than larger organizations [24]. SMEs can promptly engage the lean team members in the shortest time to discuss improvements and implementation needs, and the lean leader can make timely decisions for emergency situations. The simple structures in SMEs allow flexibility in the LM implementation, which is easily adaptable to process changes. Also, the strong organizational culture in SMEs helps to ease the launch of the LM implementation project. Management tracks the changes and manages the duty of employees to ensure the job is performed efficiently. Few numbers of employees in SMEs can rapidly cultivate strong cooperation and tend to engage in a team. They are easily motivated and work towards the same goals. On the other hand, staff are multitaskers and willing to support each other to ensure the success of $\mathrm{LM}$ implementation in $\mathrm{M} \& \mathrm{E}$ SMEs. The proposed framework utilizes $65 \mathrm{LM}$ elements to deal with the various shortcomings of the frameworks [35]. Lean implementation framework proposes appropriate practices and decision tools assigned to each phase has been developed from a structured literature review [27]. Table 3 shows the review of general LM implementation process steps presented in case SMEs. All three case SMEs are using the top-down approach in their LM implementation, and there is no specific standard framework or steps used.

In summary, all three cases SMEs adopt different approaches and process steps in their LM implementation journey. Therefore, the LM results are also varying from each other. Although LM has been implemented to a certain extent, but there is still a lack of good understanding of lean concepts and human-related factors which often lead to lean failures. The people development system conceptual framework emphasized on three integration elements namely Key Performance Indicators (KPI), respect for people and, skill and knowledge was developed to enhance the employee's problem-solving capability in lean process management implementation [36]. They are some common practices that have been seen across these three companies, such as communication for job distribution, recognize the need for changes, starting with a pilot project, identify the waste of improvement area, lean progress monitoring, and top management review for approval. These standard process steps or lean practices listed are not performed in the chronological order and the case SMEs are flexible to adapt based on their prioritization. The analysis of the LM implementation methodology is essential in the LM framework development, so that the proposed framework can be 
fitted into the SME's lean practices.

\subsection{LM Implementation Framework for M\&E SMES}

The interview respondents highlighted that the development of a comprehensive LM implementation framework specifically for M\&E SMEs is essential to serve as practical guidance and systematic outline to follow in an effective way. The success of LM experiences in M\&E SMEs can improve the operational cost savings and satisfy the customer requirements. The proposed framework focuses on the low to moderate level of lean adoption to suit their degree of adaptability and organizational maturity. The case companies already have some years of expertise in lean project implementation experiences, so the LM framework is designed to enhance their requirements. This framework is covering the entire company from the top management level until the bottom level of production shop floor employees. LM implementation strategic framework providing the top management for an overview operational planning of the LM implementation in aligning with the company policies and lean goals. The overall masterplan outline is developed to have a glimpse of LM implementation in the company within a specific timeline. Top management shall take the lead to kick-off the LM implementation, provide the required lean resources, and make the key decision to endorse the result. Middle management act as the intermediate connection between the top management and bottom management in lean project coordination. Bottom management shall communicate effectively with the shop floor employees for the requirement and work closely on the execution process by providing suitable coaching in real-life problem-solving. The proposed LM implementation framework is divided into the sequential four stages as following and the process steps were presented in Table 4:

(1) Pre-implementation (Plan): lean problems identification and project planning

(2) Implementation (Do): lean training and project implementation

(3) Evaluation: Lean result (Check): lean result performance analysis and management review

(4) Post Implementation (Act): continuous improvement and sustain a lean culture

Table 3. Review of LM implementation process steps in case SMEs

\begin{tabular}{|c|c|c|c|}
\hline Company Name & A & B & $\mathrm{C}$ \\
\hline $\begin{array}{l}\text { Establish the lean policy and } \\
\text { objectives }\end{array}$ & - & $x$ & $x$ \\
\hline Form the lean implementation committe & - & $x$ & $x$ \\
\hline Communication for job distribution & $x$ & $x$ & $x$ \\
\hline Recognize the need for changes & $x$ & $x$ & $x$ \\
\hline Kick-off meeting and orientatio & - & $x$ & $x$ \\
\hline Starting with a pilot project & $x$ & $x$ & $x$ \\
\hline Identify lean indicators & - & $x$ & - \\
\hline Lean project planning framework for changes & - & $x$ & - \\
\hline Assess the current lean level and gaps analysis & - & $x$ & - \\
\hline Lean principles and tools training to employees & - & $x$ & $x$ \\
\hline Identify the waste of improvement area & $x$ & $x$ & $x$ \\
\hline Lean progress status monitoring and feedback & $x$ & $x$ & $x$ \\
\hline Lean data collection and data analysis & - & $\mathrm{x}$ & - \\
\hline Lean result review & - & $x$ & $x$ \\
\hline Lean impact assessment & - & - & $x$ \\
\hline $\begin{array}{l}\text { Top management review and } \\
\text { approval }\end{array}$ & $x$ & $x$ & $x$ \\
\hline Lean practices standardizations and sustaining & - & $\mathrm{x}$ & - \\
\hline Extension the scope with large scale projects & - & $x$ & $x$ \\
\hline Documentation of the actions & - & $x$ & $x$ \\
\hline Continuous improvement for perfection & - & - & $x$ \\
\hline
\end{tabular}

Note: $\mathrm{A}(\mathrm{X})$ indicates that the step was carried out while a (-) denotes that it was not. 
The SIPOC (Supplier, Input, Process, Output, and Customer) methodology is the simplest and easiest way to understand the process flow involved in the supply chain [37]. Understanding the need for change in terms of customer value perspective and define the targeted problems is the pre-requisite

Table 4. The proposed framework for LM implementation in M\&E SMES

\begin{tabular}{|c|c|c|c|}
\hline $\begin{array}{l}\text { Stage 1: Pre-implementation } \\
\text { (Plan) }\end{array}$ & $\begin{array}{l}\text { Stage 2: Implementation } \\
\text { (Do) }\end{array}$ & $\begin{array}{l}\text { Stage 3: Evaluation } \\
\text { (Check) }\end{array}$ & $\begin{array}{l}\text { Stage 4: Post-implementation } \\
\text { (Act) }\end{array}$ \\
\hline $\begin{array}{l}\text { a) Understand the needs and } \\
\text { requirements } \\
\text { - Define the needs for change, } \\
\text { SIPOC } \\
\text { - Specific the value, oice of } \\
\text { customer }\end{array}$ & $\begin{array}{l}\text { a) Lean knowledge training } \\
\text { - Lean principles, concepts } \\
\text { - Employee thinking mindset } \\
\text { cultivation } \\
\text { - Early lean cultural change }\end{array}$ & $\begin{array}{l}\text { a) Lean process/product } \\
\text { monitoring } \\
\text { - Control chart, Kanban, visual } \\
\text { display } \\
\text { - Employee feedback and react } \\
\text { to the problems faced } \\
\text { - Control the performances }\end{array}$ & $\begin{array}{l}\text { a) Lean achievement celebration } \\
\text { - Reward recognition, } \\
\text { motivation, lessons learned }\end{array}$ \\
\hline
\end{tabular}

b) Define the p oblems statements clearly

- Brainstorm ideas, communication

- Lesson learned review, adopt the $5 \mathrm{~W} 1 \mathrm{H}$ approach

- Form the current state, "As Is"

c) Select the targeted problems and areas

- Pareto analysis of defects and wastes identificatio

- Process fl w chart mapping,

Gemba walk, management review b) Lean change management

- Early lean cultural change

- Promote lean awareness

- Effecti e communication

c) Selection of suitable lean tools

- Basic lean tools training

- Lean training skills matrix

- Competency assessments b) Data collection

- Check sheet recording

- Collect performance

measurement data b) Continuous improvement - Brainstorm ideas, benchmarking

- Create the "To Be" state future roadmap

- Implement Kaizen, PDCA cycle d) Form the lean committe

- Small lean team

(5 to 10 persons)

- Teamwork, define the responsibility and roles d) Conduct the lean risk assessment

- Review the risks, perform gap analysis

- If have no risk, proceed to the next step

- If have risk, go back to

step 1 e) for re-planning

e) Start lean pilot projects

- Employees involvement

- Employees empowerment

- Operational planning

- Process management c) Data analysis

- Scatter diag am, histogram

- Statistical/descriptive data analysis

- Process capability Index

(Cp\& Cpk) c) Extend for large scale

- Expand to other critical areas d) Lean result evaluation

- Management review

- Key decision making by senior management

- Identify the risk and opportunity for improvement

e) Does the lean goal achieve effecti ely?

- If yes, proceed to the next step

- If no, go back to step 2 d) to assess the risks d) Assess the employee performances, KPI

- Lean skill expertise assessments * Is the performance goal meet? - If no, go back to step 2 a) or 2 c) for re-train - If yes, proceed to next steps for advance skills upgrade enhancement

e) Employee skill upgrade program

- Train the employee to become a trainer or expert in lean fiel - Knowledge sharing and retention

-Resource planning (cost,

people, facility)

-Define the lean policy

(SMART goals)

f) Select the suitable lean indicators measurement

- Select the critical lean

parameters monitoring

- Define lean performance me surement matrix f) Standardize the lean practices

- Documentation to lock down the successful lean results - SOP creation.

- Train and communicate to employees follow SOP f) Sustain the good lean practices for long term

- Create the real lean cultures,

control plan

- Audits assessments

- Customer satisfaction

- Strategy to strengthen the lean integrated management system 
for LM project selection. The LM implementation framework usually starts with a pilot-scale and small group of relevant employees due to the limited resources of SMEs. LM implementation will be designed to embed into the employee's daily jobs function as this integration will increase the employee's direct involvement and they will feel the benefits of lean bring into their workplaces. An effective communication process plays a vital role at all levels in ensuring the success of LM implementation [38]. The shop floor employees will take the initiative to feedback the problems directly to their superior and discuss the working solutions to mitigate the risks via a bottom-up approach. M\&E SMEs can integrate the LM implementation structure introduced into the company management system and align with the current working methods. It is essential to assess the link between lean readiness, the approach taken and the level of sustainability achieved in LM implementation [39]. Early lean engagement and change management for the employee towards LM implementation project readiness can create a high impact on achieving the sustainable lean result. The right selection of appropriate lean parameters (inputs) on the targeted main areas in primary waste management (Muda, Mura, Muri) is of utmost importance as this need to align with the key performance assessment metrics (outputs) in determining the efficacy of the results of LM implementation versus project goals. The selection of suitable lean tools is essential, as not every lean tool is ideal for SMEs. The feasible lean tools selection for LM implementation in SMEs are categorized into the basic, intermediate, and advanced levels based on their lean maturity level [40]. The four critical success factors for LM implementation in SMEs are leadership and management, finance, skills and expertise, and organizational culture [2]. Besides that, the soft elements and employee lean knowledge enhancement are the critical key element in the determination of LM implementation successfully that cannot be neglected. The internal trainer should have a robust lean knowledge understanding and able to educate this lesson to the others by conducting the intensive lean workshop. Lean training skills matrix is developed to assess the employee competency level based on the KPI setting. A new physical simulation game framework was introduced to provide an interesting hands-on training experience to the trainees to get a deeper understanding of the lean principles [41]. This will increase the employee's acceptance towards lean and inspire the creative mindset in the lean application. A Swedish national program experienced the LM implementa- tion in SMEs in three major areas of activity: spreading inspiration and knowledge, education in lean production, and coaching methodology [42]. PDCA (Plan-Do-Check-Act) cycle is a reliable tool used for continuous improvement in kaizen workshops to define the current state and plan the execution actions systematically to achieve the result [43]. This framework structure consists of 23 easy to follow elements or steps, with using the PDCA approaches integrated into four phases of implementation. PDCA cycle is a systematic and repeating four-stage method for continually improving the process [37]. This can built-up the strong confidence for SMEs lean practitioner and strengthen the sustainability of LM practices for the long term after the post-implementation.

\subsection{Features of LM Implementation Framework for M\&E SMEs}

The notion of establishing the LM implementation framework which provides the main elements (steps, tools and success factors) has been introduced which compliant with the set of seven characteristics that are considered suitable for SMEs [12]. The three highlighted features in the proposed LM framework are building the lean expert team, lessons-learned review and documentation, and lean implementation monitoring and controlling [27]. The main characteristics of the proposed framework are emphasized on the importance of LM awareness, identify lean drivers and barriers, identify appropriate tools, the involvement of all stakeholders, understand the entire supply chain activities to improve the performance matrices, and reward system for employees [33]. This proposed LM framework is further enhanced by introducing four emerging elements to close-up the existing gaps. First, it specifies value from the standpoint of the end customer at the very beginning first step in Stage 1, based on the first step outlined in 5 key lean principles. It is essential to define the customer's needs for a specific product and how SMEs can meet the requirements or expectations to maximize the gains while minimizing waste. The lean change management is emphasized in Stage 2 before starting the lean project implementation in SMEs. All employees should be engaged in the lean readiness towards the early cultural change adaption and play their roles in contributing to the lean transformation in the company. The lean process monitoring, performance measurement, data analysis and result evaluation are introduced in Stage 3 to facilitate the key decision making in management review. The human element is one of the critical success factors in LM 
which require to be integrated into in SMEs company management system. The assessment of employee's performance based on the KPI system established in Stage 4 can enhance the lean knowledge sharing and retention in the company. The upgrading of employees in lean skills and expertise can strengthen the sustainability of LM in SMEs.

The proposed LM implementation framework is a simple and practical guideline that aims to overcome the shortcomings of the existing frameworks. The main features of this framework are presented in the following:

- This is the self-explanatory framework, which is easy to understand and followed.

- LM implementation processes are integrated with the company management system and working culture.

- The case studies company's current LM good practices are reviewed and adapted.

- It has introduced the lean critical success factors needed for application in SMEs.

- It has included feasible lean practices and basic quality tools to enhance adoption.

- It focuses on the customers in value creation by understanding their needs and satisfies the requirements.

- It focuses on the employee's lean knowledge and skills development. Lean thinking mindset is instilled in the early stage, and relevant lean tools application training is conducted before starting the lean projects.

- Employee competency levels are assessed via performance measurement systems.

- It suits SMEs flexible characteristic and lean suitability level with creating the continuous feedback loop or checkpoint to assess the achievement of lean goals.

- Employee involvement and empowerment are emphasized with teamwork, open feedback, reward recognition, motivation, communication, and skill upgrade.

- Lean is enhanced through continuous improvement and sustainable performances.

- Top management leadership commitment is emphasized throughout every stage of LM implementation to ensure the management system meet the company goals.

\subsection{Validation of LM Implementation Framework for M\&E SMEs}

An academician with extensive experience in LM field from the local university and SMEs case companies had validated the proposed LM implementation framework and its feature description. The valuable comments were embraced and documented as shown in the finalized framework (see Table 4). Overall, the proposed LM framework is understandable, has covered most of the critical elements required for implementation and is considered to be well incorporated into M\&E SMEs to suit their needs. Five validation questions were adopted as follows [44]:

(1) Has the framework covered most of the essential LM implementation elements?

(2) How understandable is this framework?

(3) How feasible is this implementable framework for M\&E SMEs?

(4) Any comment on the features and/or drawbacks of this framework?

(5) Suggestion for improvement (if any).

\section{Conclusions}

SMEs are essential to the national building development and creation of job employment opportunities for a country. However, SMEs are always lag during the LM implementation as compared to other large organizations. The lean results obtained are still very weak in the case SMEs mainly due to the poor lean implementation or wrong adoption for lean approaches. The main objective of this research is to develop a suitable LM implementation framework for M\&E SMEs for them to succeed in their lean journey. Open-ended questions are used when conducted the semi-structured interview with the selected multiple case study of M\&E SMEs respondents. Lean techniques and basic quality tools are included in the framework for lean practitioners to ease the lean implementation. The proposed framework consists of four implementation stages presented in the easy to follow sequential steps with adopting the PDCA approach. The LM implementation is integrated with the company management system, so that lean application is well connected to the current work practices to enhance the effectiveness of problem-solving. M\&E SMEs management must emphasize much on the critical success factors and adopt the right approach of LM implementation methodology during their lean implementation journey to increase the chances of success. The development of 
the new LM implementation operational framework serves as a practical methodology and straightforward guidance in the context of M\&E SMEs for industrial applications.

This study has made three major contributions. First, the current approaches and LM implementation process steps in case SMEs were examined. LM implementation framework is constructed based on the real-life LM experiences derived from these actual practices with enhancement elements. This can assist SMEs lean practitioner in adopting the right approaches and applying good LM practices in their workplace. Second, a lot of useful opinions were gathered from the bottom management level up to senior management level respondents. The active involvement of well-trained employees from all levels and performance development is the key success of LM implementation. Third, the proposed LM framework is developed based on the organizational lean maturity level and adaptable to suit the characteristic of SMEs. M\&E SMEs can assess the current methodology adopted in their LM implementation and work out the proper LM strategy planning for continuous improvement to a higher level. The limitation of this study is this framework is still not yet practically implemented by any of the SMEs for validation. It is strongly suggested that this framework can be further improved via actual case study application or action research to verify the effectiveness. Lastly, future research could be expanded to cover other manufacturing sectors in SMEs for broader generalization, including shop-floor employees to validate the findings for improving the framework.

\section{Acknowledgements}

The authors would like to thank the SMEs case companies for their strong support given and wish to express our gratitude to Universiti Teknikal Malaysia Melaka (UTeM).

\section{Funding}

This research did not receive any specific grant from funding agencies in the public, commercial, or not-for-profit sectors.

\section{References}

[1] A. Pearce, D. Pons, and T. Neitzert, "Implementing leanOutcomes from SME case studies," Oper. Res. Perspect., vol. 5, pp. 94-104, 2018, https://doi.org/10.1016/j.orp.2018.02.002.
[2] P. Achanga, E. Shehab, R. Roy, and G. Nelder, "Critical success factors for lean implementation within SMEs," J. Manuf. Technol. Manag., vol. 17, no. 4, pp. 460-471, 2006, https://doi.org/10.1108/17410380610662889.

[3] D. T. Matt and E. Rauch, "Implementation of lean production in small sized enterprises," Procedia CIRP, vol. 12, pp. 420-425, 2013, https://doi.org/10.1016/j.procir.2013.09.072.

[4] J. Bhamu and K. S. Sangwan, "Lean manufacturing: Literature review and research issues," Int. J. Oper. Prod. Manag., vol. 34, no. 7, pp. 876-940, 2014, https://doi.org/10.1108/IJOPM-08-2012-0315.

[5] I. Veža, N. Gjeldum, and L. Celent, "Lean Manufacturing Implementation Problems in Beverage Production Systems," Int. J. Ind. Eng. Manag., vol. 2, no. 1, pp. 21-26, 2011.

[6] N. Nordin and H. M. Belal, "Change agent system in lean manufacturing implementation for business sustainability," Int. J. Supply Chain Manag., vol. 6, no. 3, pp. 271-278, 2017.

[7] I. S. Mohammad and C. F. Oduoza, "Lean-excellence business management for manufacturing SMEs focusing on KRI,” Int. J. Product. Perform. Manag., 2019, https://doi.org/10.1108/IJPPM-11-2018-0389.

[8] S. Azuan, S. Ahmad, W. Khairuzzaman, and W. Ismail, "Lean manufacturing, culture, lean culture," J. Bus. Manag., vol. 1, no. 1, pp. 6-14, 2017.

[9] SME Corp. Malaysia Secretariat. "Guideline for SME Definition.” [Online]. Available:https://www.smecorp. gov.my/images/pdf/2020/Guideline-SMEDefinition _ updated.pdf [Accessed: 10-May-2020].

[10] Department of Statistics Malaysia. "Press Release Small and Medium Enterprises (SMEs) Performance 2018." [Online]. Available: https://www.dosm.gov.my/v1/index. php? $\mathrm{r}=$ column $/$ cthemeByCat\&cat $=159 \&$ bul_id=R0V ka2RpeVJ0cUlpR3BqdjhudDZhdz09\&menu_id= TE5CRUZCblh4ZTZMODZIbmk2aWRRQT09 [Accessed: 10-Dec-2019].

[11] Malaysian Investment Development Authority. "Malaysia's Machinery \& Equipment and Engineering Supporting Industries." [Online]. Available: https://www. mida.gov.my/home/administrator/system_files/modules/ photo/uploads/20191024164247_M\&E\%202019\%20 edition.pdf [Accessed: 10-Dec-2019].

[12] A. Belhadi, F. E. Touriki, and S. El Fezazi, "A framework for effective implementation of lean production in small and medium-sized enterprises,” J. Ind. Eng. Manag., vol. 9, no. 3, pp. 786-810, 2016, https://doi.org/10.3926/jiem.1907.

[13] M. Almanei, K. Salonitis, and Y. Xu, "Lean Implementation Frameworks: The Challenges for SMEs," Procedia CIRP, vol. 63, pp. 750-755, 2017, https://doi.org/10.1016/j.procir.2017.03.170.

[14] R. Ulewicz and R. Kuc口ba, "Identification of problems of implementation of Lean concept in the SME sector," Eng. Manag. Prod. Serv., vol. 8, no. 1, pp. 19-25, 2016, https://doi.org/10.1515/emj-2016-0002.

[15] N. D. Minh and N. T. Van Ha, "Made in Vietnam' Lean Management Model for Sustainable Development of Vietnamese Enterprises," Procedia CIRP, vol. 40, pp. 602607, 2016, https://doi.org/10.1016/j.procir.2016.01.141.

[16] T. Ohno, Toyota Production System: Beyond Large-Scale Production. Portland, OR, USA: Productivity Press, 1988.

[17] J. P. Womack, D. T. Jones, and D. Roos, The Machine that Changed the World. New York, NY, USA: Rawson Associates, 1990.

[18] J. K. Liker, The Toyota Way: 14 Management Principles from the World's Greatest Manufacturer. New York, NY, USA: McGraw-Hill, 2004.

[19] J. P. Womack and D. T. Jones, Lean Thinking: Banish 
Waste and Create Wealth in Your Corporation. New York, NY, USA: Simon \& Schuster, 2003.

[20] N. A. A. Bakar, T. Z. Mat, F. M. Fahmi, and S. T. Urus, "Lean Management Practices and its Effect on Malaysian Local Government Performance," Manag. Account. J., vol. 12, no. 2, pp. 1-20, 2017.

[21] Y. C. Wong and K. Y. Wong, "A Lean Manufacturing Framework for the Malaysian Electrical and Electronics Industry," Proc. 3rd Int. Conf. Inf. Financ. Eng., vol. 12, pp. 30-34, 2011.

[22] S. M. Yusof and E. Aspinwall, "Total quality management implementation frameworks: Comparison and review," Total Qual. Manag., vol. 11, no. 3, pp. 281-294, 2000, https://doi.org/10.1080/0954412006801.

[23] M. Dora, M. Kumar, and X. Gellynck, "Determinants and barriers to lean implementation in food-processing SMEs A multiple case analysis," Prod. Plan. Control, vol. 27, no. 1, pp. 1-23, 2016, https://doi.org/10.1080/09537287.2015.1 050477.

[24] S. M. Yusof and E. Aspinwall, "Conceptual framework for TQM implementation for SMEs," TQM Mag., vol. 12, no. 1, pp. 31-36, 2000, https://doi.org/10.1108/ 09544780010287131.

[25] A. Belhadi, Y. B. M. Sha'ri, F. E. Touriki, and S. El Fezazi, "Lean production in SMEs: literature review and reflection on future challenges," J. Ind. Prod. Eng., vol. 35, no. 6, pp. 368-382, 2018, https://doi.org/10.1080/21681015.2018.150 8081 .

[26] L. Goehnera, L. C. B. B. Mello, and R. A. M. Bandeira, "Lean Manufacturing Implementation for Multinational Companies With Production Subsidiary in Brazil: Development of a Roadmap," Int. J. Lean Think., vol. 7, no. 1, pp. 26-46, 2016.

[27] S. Mostafa, J. Dumrak, and H. Soltan, "A framework for lean manufacturing implementation," Prod. Manuf. Res., vol. 1, no. 1, pp. 44-64, 2013, https://doi.org/10.1080/2169 3277.2013.862159.

[28] M. Almanei, K. Salonitis, and C. Tsinopoulos, "A conceptual lean implementation framework based on change management theory," Procedia CIRP, vol. 72, pp. 1160-1165, 2018, https://doi.org/10.1016/j.procir.2018. 03.141.

[29] N. V. K. Jasti and R. Kodali, "Lean manufacturing frame works: review and a proposed framework," Eur. J. Ind. Eng., vol. 10, no. 5, p. 547, 2016, https://doi.org/10.1504/ ejie.2016.078799.

[30] R. C. Mamat, B. Md Deros, M. N. Ab Rahman, M. K. Omar, and S. Abdullah, "Soft lean practices for successful lean production system implementation in malaysia automotive smes: A proposed framework," J. Teknol., vol. 77, no. 27, pp. 141-150, 2015, https://doi.org/10.11113/ jt.v77.6910.

[31] Z. H. Ainul Azyan, V. Pulakanam, and D. Pons, "Success factors and barriers to implementing lean in the printing industry: A case study and theoretical framework, J. Manuf. Technol. Manag., vol. 28, no. 4, pp. 458-484, 2017, https:// doi.org/10.1108/JMTM-05-2016-0067.

[32] H. Afonso and M. D. R. Cabrita, "Developing a lean supply chain performance framework in a SME: A perspective based on the balanced scorecard," Procedia Eng., vol. 131, pp. 270-279, 2015, https://doi.org/10.1108/JMTM-052016-0067.

[33] J. Bhamu and K. S. Sangwan, "A framework for lean manufacturing implementation,” Int. J. Serv. Oper. Manag., vol. 25, no. 3, pp. 313-333, 2016.

[34] A. A. Osman, A. A. Othman, and M. K. I. A. Rahim, "Lean Manufacturing Adoption in Malaysia: A Systematic Literature review," Int. J. Supply Chain. Oper. Manag. Logist., vol. 1, no. 1, pp. 1-35, 2020.
[35] G. Anand and R. Kodali, "Analysis of Lean Manufacturing Frameworks,” J. Adv. Manuf. Syst., vol. 09, no. 01, pp. 1-30, 2010, https://doi.org/10.1142/s0219686710001776.

[36] A. P. Puvanasvaran, M. H. M. A. Megat, S. H. Tang, M. R. Muhamad, and A. M. S. Hamouda, "A review of problem solving capabilities in lean process management," Am. J. Appl. Sci., vol. 5, no. 5, pp. 504-511, 2008.

[37] S. Soares and L. Teixeira, "Lean information management in industrial context: An experience based on a practical case,” Int. J. Ind. Eng. Manag., vol. 5, no. 2, pp. 107-114, 2014.

[38] P. Puvanasvaran, H. Megat, T. S. Hong, and M. M. Razali, "The roles of communication process for an effective lean manufacturing implementation,” J. Ind. Eng. Manag., vol. 2, no. 1, pp. 128-152, 2009, https://doi.org/10.3926/ jiem.2009.v2n1.p128-152.

[39] Z. Radnor, "Implementing Lean in Health Care: Making the link between the approach, readiness and sustainability," Int. J. Ind. Eng. Manag., vol. 2, no. 1, pp. 1-12, 2011.

[40] A. M. N. Rose, B. M. Deros, and M. N. A. Rahman, "Development of framework for lean manufacturing implementation in SMEs," 11th Asia Pacific Ind. Eng. Manag. Syst. Conf. 14th Asia Pacific Reg. Meet. Int. Found. Prod. Res., vol. December, pp. 1-5, 2010.

[41] I. Da Silva, A. R. Xambre, and R. B. Lopes, "A simulation game framework for teaching lean production,” Int. J. Ind. Eng. Manag., vol. 4, no. 2, pp. 81-86, 2013.

[42] L. Medbo and D. Carlsson, "Implementation of Lean in SME, experiences from a Swedish national program," Int. J. Ind. Eng. Manag., vol. 4, no. 4, pp. 221-227, 2013.

[43] N. Štefanić, N. Tošanović, and M. Hegedić, "Kaizen work shop as an important element of continuous improvement process," Int. J. Ind. Eng. Manag., vol. 3, no. 2, pp. 93-98, 2012.

[44] T. F. Chay, "A Bottom-up Lean Implementation Study at a Malaysian Automotive Parts Manufacturer," M.S. thesis, 2014. [online] Available at: School of Applied Sci., Cranfield Univ., Cranfield, Bedfordshire, UK, 2014. [Online]. Available: https://dspace.lib.cranfield.ac.uk/ bitstream/handle/1826/8608/Chay_T_F_Thesis_2013. pdf? sequence $=1 \&$ isAllowed $=\mathrm{y}$ 